Check for updates

Cite this: RSC Adv., 2017, 7, 53481

Received 21st September 2017 Accepted 13th November 2017

DOI: $10.1039 / \mathrm{c} 7 \mathrm{ra10484g}$

rsc.li/rsc-advances

\section{Proton conducting electrospun sulfonated polyether ether ketone graphene oxide composite membranes $\uparrow$}

\author{
Jose Luis Reyes-Rodriguez, ${ }^{a}$ Jorge Escorihuela, ${ }^{b}$ Abel García-Bernabé, ${ }^{b}$ \\ Enrique Giménez, ${ }^{\mathrm{C}}$ Omar Solorza-Feria ${ }^{a}$ and Vicente Compañ (D) *b
}

\begin{abstract}
A series of novel composite membranes, based on sulfonated poly(ether ketone) (SPEEK) with a graphene oxide (GO) layer, were prepared. One contained a GO layer sandwiched between the SPEEK-polyvinyl alcohol (PVA) matrix (SPEEK/PVA(GG), and another deposited thin layers of GO on the nanofibers of SPEEK-polyvinyl butyral (PVB), with both sandwiched in the phase matrix of SPEEK-PVA (SPEEK/ PVA@GO-NF). Various nanofiber thicknesses were studied by varying the electrospinning time. The prepared composite membranes with different nanofiber thicknesses were characterized by scanning electron microscopy, water uptake, ionic exchange capacity, thermogravimetric analysis, mechanical properties and proton conductivity. Our results showed that the proton conductivity of SPEEK/PVA@GO membranes increased with temperature, from $1 \times 10^{-3} \mathrm{~S} \mathrm{~cm}^{-1}$ at $30^{\circ} \mathrm{C}$ to $8.3 \times 10^{-3} \mathrm{~S} \mathrm{~cm}^{-1}$ at $130{ }^{\circ} \mathrm{C}$. These conductivity values are higher than those observed for the membrane with SPEEK/PVA@GO-NF nanofibers. However, a conductivity comparison of the different thicknesses of SPEEK/PVA@GO-NF nanofibers allowed us to conclude that conductivities increase with nanofiber thickness at all temperatures. Finally, the calculated activation energy of the SPEEK/PVA@GO membrane $\left(1.4 \mathrm{~kJ} \mathrm{~mol}^{-1}\right)$ was found to be one order of magnitude lower than that for pure SPEEK/PVA $\left(17.3 \mathrm{~kJ} \mathrm{~mol}^{-1}\right)$. This reduction indicated that the influence of temperature on the conductivity decreases when $G O$ is inserted into SPEEK/PVA membranes. In the case of the SPEEK/PVA@GO-NF membrane, the activation energy decreased as a function of the nanofiber network's thickness.
\end{abstract}

\section{Introduction}

Proton transfer plays a crucial role in a wide range of chemical and biological processes, such as enzyme reactions, photosynthesis and respiration, as well as in technological applications, such as, fuel cells, chemical sensors and electrochemical devices. ${ }^{1}$ In proton exchange membranes (PEMs), the device performance is directly dependent on the velocity of the proton transfer (i.e., proton conductivity). ${ }^{2,3}$ Proton exchange membrane fuel cells (PEMFCs) are promising electrochemical energy conversion devices for transportation and stationary

\footnotetext{
${ }^{a}$ Departamento de Química - Centro de Investigación y de Estudios Avanzados del I.P.N., Av. IPN 2508, Col. San Pedro Zacatenco, 07360 México D.F., Mexico

${ }^{b}$ Escuela Técnica Superior de Ingenieros Industriales - Departamento de Termodinámica Aplicada, Universitat Politècnica de València, Camino de vera $s / n$, 46020 Valencia, Spain. E-mail: vicommo@ter.upv.es; Fax: +34 9638779 24; Tel: +34963879328

${ }^{c}$ Escuela Técnica Superior de Ingenieros Industriales - Departamento de Ingeniería Mecánica y de Materiales, Universitat Politècnica de València, Camino de vera $s / n$, 46020 Valencia, Spain

$\dagger$ Electronic supplementary information (ESI) available: SEM images, electrochemical impedance spectroscopy figures and mechanical properties table. See DOI: 10.1039/c7ra10484g
}

applications, which use proton conductive polymer membranes as electrolytes. ${ }^{4-6}$ An ideal PEMFC possesses high proton conductivity, low gas and liquid permeability, excellent stability at a high temperature, mechanical strength and a low cost. ${ }^{7}$ In this regard, Nafion membranes, based on perfluorosulfonic acid polymers, have been widely used as PEMs due to their excellent proton conductivity and high chemical stability. ${ }^{8}$ However, Nafion membranes have several drawbacks, such as low proton/vanadium ion selectivity, high costs and a dramatic reduction in the proton conductivity above $80{ }^{\circ} \mathrm{C}$, which blocks its use for large-scale applications. ${ }^{9}$ Therefore, the search and development of low-cost PEMs with high conductivity at elevated temperatures is a critical issue in PEMFCs.

As a consequence, many non-perfluorinated membranes, such as sulfonated poly(ether sulfone) (SPES), ${ }^{\mathbf{1 0 , 1 1}}$ sulfonated poly(arylene ether sulfone) (SPAES), ${ }^{12}$ sulfonated polybenzimidazoles $(\mathrm{SPBI}){ }^{13,14}$ sulfonated polyimides (SPI), ${ }^{15}$ sulfonated polyphosphazenes (SPP), ${ }^{16}$ sulfonated poly(ether ketone) (SPEEK) ${ }^{17,18}$ and other alternative polymers, ${ }^{\mathbf{1 9}}$ have emerged as attractive candidates for replacing Nafion membranes due to their lower costs as well as higher thermal and mechanical stability.

In recent years, the SPEEK polymer has emerged as a noble substitute for Nafion membranes due to its high thermal and 
chemical stability, and low cost for application as a precursor of protonic exchange membranes operating at intermediate temperatures (100 to $150{ }^{\circ} \mathrm{C}$ ) in PEMFCs. ${ }^{20-22}$ However, the physical and chemical properties of SPEEK membranes are highly dependent on the degree of sulfonation (DS). ${ }^{23}$ In this regard, SPEEK membranes with high DS exhibit high proton conductivity, although high DS values lead to poor mechanical stability. ${ }^{24}$

In the past few years, different approaches have been developed to improve the properties and performance of PEMFCs, particularly SPEEK membranes. ${ }^{25-27}$ Among them, the dispersion in the polymeric matrix of nanomaterials based on inorganic fillers possessing proton-conducting groups, ${ }^{28-30} \mathrm{such}$ as zeolites, ${ }^{31}$ carbon nanotubes, ${ }^{32}$ silicon nanoparticles, ${ }^{33}$ heteropolyacids $^{34}$ and many others, has emerged as an attractive strategy. In addition, graphene oxide (GO) has particularly received significant attention due to its excellent physical and chemical properties. ${ }^{35}$ In this regard, GO has emerged as a potential candidate in proton-conducting processes due to its high stability and the presence of a variety of oxygenated functional groups $(-\mathrm{O}-,-\mathrm{OH}$, and $-\mathrm{COOH})$ in its structure, which seem to participate in the formation of one-dimensional hydrogen-bonded channels for proton transport. ${ }^{36}$ Recently, the incorporation of GO was found to improve the proton conductivity of PEM because the acid-base interactions between the sulfonic acid groups of the polymer matrix and the basic groups of functionalized GO are involved in the generation of additional proton conductivity mechanisms. ${ }^{37-43}$

In this work, we report the preparation and application of a series of SPEEK-polyvinyl alcohol (PVA) nanocomposite membranes containing GO and SPEEK-polyvinyl butyral (PVB)based nanofibers sandwiched inside two GO layers. These nanofibers were fabricated using the electrospinning method, which has received considerable attention in the preparation of PEMs during the past few years. ${ }^{44}$ The corresponding nanocomposite membranes were characterized by scanning electron microscopy (SEM), water uptake, ionic exchange capacity, thermogravimetric analysis, mechanical properties and proton conductivity. In this study, we investigated two types of membranes: one with the GO layer sandwiched between the matrix phase of SPEEK-PVA, and the other depositing thin layers of GO on the nanofibers of SPEEK 70 wt $\%-\mathrm{PVB}_{30}$ wt $\%$ with different thicknesses, with both sandwiched in the phase matrix of SPEEK-PVA. The proton conductivity of different composite SPEEK/PVA@GO and SPEEK/PVA@GO-NF membranes was measured via impedance spectroscopy in the temperature range of between 30 and $130{ }^{\circ} \mathrm{C}$.

\section{Experimental}

\subsection{Materials}

PEEK (VICTREX® PEEK $450 \mathrm{PF)}$ ) was acquired from Victrex, Inc. in the form of a powder $(50 \mathrm{~mm})$ with a molecular weight $\left(M_{\mathrm{w}}\right)$ of 39200 and a density of $1.30 \mathrm{~g} \mathrm{~cm}^{-3}$. PEEK was dried at $150{ }^{\circ} \mathrm{C}$ for $3 \mathrm{~h}$ in an oven as specified in its technical data sheet. PVB (Butvar ${ }^{\circledR}$ B-98 powder) was purchased from Sigma-Aldrich. Granulated PVA (Mowiol@ 28-99 grade) was donated by the
Kuraray Europe GmbH Company (Frankfurt, Germany). Concentrated sulphuric acid $\left(\mathrm{H}_{2} \mathrm{SO}_{4}\right)$ with a specified concentration of 95 to $98 \mathrm{wt} \%$ was purchased from Scharlau. $N, N$ Dimethylacetamide (DMAc) 99.8\% solvent was purchased from Sigma-Aldrich. The PVB, PVA, sulfuric acid and DMAc were used as received.

\subsection{Synthesis of graphene oxide (GO)}

GO was synthesized from graphite powder through a modified Hummer's method ${ }^{45,46}$ as described briefly as follows: in a pretreatment step that ensured complete oxidation, concentrated $\mathrm{H}_{2} \mathrm{SO}_{4}(12 \mathrm{ml})$ was heated to $80{ }^{\circ} \mathrm{C}$ in a $300 \mathrm{ml}$ beaker. $\mathrm{K}_{2} \mathrm{~S}_{2} \mathrm{O}_{8}$ $(2.5 \mathrm{~g})$ and $\mathrm{P}_{2} \mathrm{O}_{5}(2.5 \mathrm{~g})$ were added under stirring until the reactants were completely dissolved. Graphite powder ( $3 \mathrm{~g})$ was then added to the $\mathrm{H}_{2} \mathrm{SO}_{4}$ solution, and the mixture was kept at $80^{\circ} \mathrm{C}$ for $4.5 \mathrm{~h}$ using a hotplate. Subsequently, the heating was stopped, and the mixture was diluted with $0.5 \mathrm{l}$ of deionized (DI) water and left overnight. The reaction mixture was filtered and subsequently washed using a 0.2-micron Nylon Millipore filter to remove all traces of acid. The solid was then transferred to a drying dish and left overnight under ambient conditions. Pretreated graphite powder was put into cold $\left(0^{\circ} \mathrm{C}\right)$ concentrated $\mathrm{H}_{2} \mathrm{SO}_{4}(120 \mathrm{ml})$. Then, $\mathrm{KMnO}_{4}(15 \mathrm{~g})$ was added gradually under stirring, and the temperature of the mixture was kept to below $20{ }^{\circ} \mathrm{C}$ by cooling. Successively, the mixture was stirred at $35{ }^{\circ} \mathrm{C}$ for $2 \mathrm{~h}$ and diluted with DI water $(250 \mathrm{ml})$. Because the addition of water in the concentrated sulfuric acid medium released a large amount of heat, the addition of water was carried out in an ice bath to keep the temperature below $50{ }^{\circ} \mathrm{C}$. After adding all of the $250 \mathrm{ml}$ of DI water, the mixture was stirred for $2 \mathrm{~h}$, and then, additional $0.7 \mathrm{l}$ of DI water was added. Shortly after the dilution with $0.7 \mathrm{l}$ of water, $20 \mathrm{ml}$ of $30 \% \mathrm{H}_{2} \mathrm{O}_{2}$ was added to the mixture, and the color of the mixture changed into brilliant yellow along with bubbling. The mixture was filtered and subsequently washed with a $1: 10 \mathrm{HCl}$ aqueous solution (1 l) to remove metal ions, followed by $1 \mathrm{l}$ of DI water to remove acid. The resulting solid was dried in air, diluted in DI water and ultrasonicated for $10 \mathrm{~min}$ until a homogeneous solution was obtained. Finally, this GO solution was centrifuged at $1500 \mathrm{rpm}$ for $10 \mathrm{~min}$ to remove the unexfoliated GO.

\subsection{Sulfonation of SPEEK}

A total of $30 \mathrm{~g}$ of dry PEEK powder was gradually dissolved in concentrated sulfuric acid at $55{ }^{\circ} \mathrm{C}$ under continuous mechanical stirring, and a concentration ratio of 5/95 (w/v) PEEK/ sulfuric was maintained. During the slow addition of the PEEK powder, the mixture changed from brown to an intense red color. After the complete dissolution of PEEK ( $\sim 45 \mathrm{~min}$ ), the polymer solution was maintained under the same temperature and stirring conditions for $12 \mathrm{~h}$. Then, the polymer solution was precipitated (using a syringe) in cold DI water under mechanical stirring to obtain thin white threads of the SPEEK. The threads were successively immersed in DI water to remove the residual sulfuric acid until the $\mathrm{pH}$ value of the washing water filtered was near 7 . The threads were dried first at $80{ }^{\circ} \mathrm{C}$ in an oven overnight to remove as much water as possible. In this step, the threads 
were merged into a yellow solid mass similar to a gelatin. This gelatin was cut into small pieces that were dried in an oven at $100{ }^{\circ} \mathrm{C}$ until a constant weight was observed. The final dark red product was stored in a sealed container to avoid the absorption of water.

\subsection{Preparation of membranes}

2.4.1. Preparation of SPEEK/PVA@GO. GO composite SPEEK/PVA membrane was prepared by adding the SPEEK/PVA solution (in DMAc) on the extended GO over the glass plate, which was subsequently dried at $80^{\circ} \mathrm{C}$ for $6 \mathrm{~h}$. Next, membranes were dried at $160{ }^{\circ} \mathrm{C}$ for $16 \mathrm{~h}$ to remove residual DMAc solvent. Finally, the membranes were dried under pressure at $140{ }^{\circ} \mathrm{C}$ for $10 \mathrm{~min}$. The thickness of the prepared GO layer was approximately 5-7 $\mu \mathrm{m}$ with an uncertainty of $1 \mu \mathrm{m}$, and the final thickness of the SPEEK/PVA-GO membranes was 200-220 $\mu \mathrm{m}$ with an uncertainty of $10 \mu \mathrm{m}$.

2.4.2. Preparation of SPEEK/PVA@GO-NF. The fabrication of SPEEK/PVB nanofibers was performed by using the electrospinning method as described in previous reports. ${ }^{47}$ The polymer solution (20 wt\% SPEEK $_{70}-\mathrm{PVB}_{30}$ in DMAc) was injected with a syringe pump with a flow rate of $0.2 \mathrm{ml} \mathrm{h}^{-1}$ to the tip of a steel capillary, which was separated by $18 \mathrm{~cm}$ from the rotating drum collector (1200 rpm). A potential difference of $20 \mathrm{kV}$ was applied between both electrodes. The electrospinning time varied from two to 14 hours with the purpose of obtaining different mat thicknesses. The obtained nanofiber mats were dried in an oven first at $80^{\circ} \mathrm{C}$ for $16 \mathrm{~h}$ and then at $160{ }^{\circ} \mathrm{C}$ for $16 \mathrm{~h}$ to remove residual DMAc solvent. Finally, the membranes were dried under pressure at $140{ }^{\circ} \mathrm{C}$ for $10 \mathrm{~min}$. The final thickness of the SPEEK/PVA-GO-SPEEK-NF membranes was 180-220 $\mu \mathrm{m}$. The composite membrane is denoted as SPEEK/PVA@GO-NF- $X$, where $X$ is the thickness of the SPEEK/PVB nanofiber mat, e.g., SPEEK/PVA@GO-NF-10 is the composite membrane with a SPEEK/PVB nanofiber mat of $10 \mu \mathrm{m}$.

\subsection{Characterization of the composite membranes}

2.5.1. Scanning electron microscopy (SEM) analysis. The morphology of the composite membranes was investigated by using a field emission scanning electron microscope (FESEM model Ultra 55, Zeiss). Cross-sectional observations were made for SPEEK/PVA composite membranes that were previously cryo-fractured in liquid nitrogen. All of the samples were coated with platinum sputtering before SEM observations were made.

2.5.2. Fourier transform infrared spectroscopy (FTIR) analysis. Fourier transform infrared spectra (FTIR) of membranes were recorded using a Jasco FT-IR spectrometer between 500 and $4000 \mathrm{~cm}^{-1}$ with a $4 \mathrm{~cm}^{-1}$ resolution and an attenuated total reflectance (ATR) cell. Backgrounds were acquired before every third sample.

2.5.3. Water uptake and swelling ratio. To evaluate the water uptake and swelling ratio of the membranes, membrane samples were first soaked in DI water at room temperature for $24 \mathrm{~h}$ and then wiped with absorbent paper to remove surface water; then, they were weighed in the dried state $\left(W_{\text {dry }}\right)$. Afterward, the membranes were dried in a vacuum oven at $100{ }^{\circ} \mathrm{C}$ for
$24 \mathrm{~h}$ and weighed again $\left(W_{\text {wet }}\right)$. The water uptake and swelling ratio of the membrane were calculated according to eqn (1) and (2):

$$
\begin{gathered}
\text { Water uptake }(\%)=\frac{W_{\text {wet }}-W_{\text {dry }}}{W_{\text {dry }}} \\
\text { Swelling thickness }(\%)=\frac{L_{\text {wet }}-L_{\text {dry }}}{L_{\text {dry }}}
\end{gathered}
$$

where $W_{\text {wet }}$ and $W_{\text {dry }}$ are the weights of the membranes after and before water absorption respectively; $L_{\text {wet }}$ and $L_{\text {dry }}$ are the thicknesses of the wet and dry membranes respectively. Three independent tests were conducted, and the average values were calculated.

2.5.4. Ion exchange capacity (IEC) and degree of sulfonation. The ion exchange capability (IEC) of the membrane was measured by using the traditional titration technique. Typically, the membranes were first dried. Subsequently, the membranes were immersed in $50 \mathrm{ml}$ saturated $\mathrm{NaCl}$ solution and stored in sealed bags for $24 \mathrm{~h}$. Afterward, the solution was filtered and then titrated with $0.01 \mathrm{~mol} \mathrm{l}^{-1} \mathrm{NaOH}$, and the IEC $\left(\right.$ meq g ${ }^{-1}$ ) was calculated according to eqn (3):

$$
\operatorname{IEC}\left(\text { meq. } \mathrm{g}^{-1}\right)=\frac{V_{\mathrm{NaOH}} \times M_{\mathrm{NaOH}}}{m}
$$

where $V_{\mathrm{NaOH}}$ is the volume $(\mathrm{ml})$ of consumed $\mathrm{NaOH}$ solution, and $C_{\mathrm{NaOH}}$ is the concentration $\left(\mathrm{mol} \mathrm{L}^{-1}\right)$ of $\mathrm{NaOH}$ solution.

The degree of sulfonation (DS) was calculated by using the following equation:

$$
\mathrm{DS}=\frac{M_{\text {SPEEK }}}{\frac{1000}{\mathrm{IEC}}-M_{\mathrm{HSO}_{3}}} \times 100
$$

where $M_{\text {SPEEK }}$ and $M_{\mathrm{HSO} 3}$ are the molecular weights of the SPEEK monomer repeat unit (288) and sulfonic group $\mathrm{HSO}_{3}(81)$ respectively, and where the IEC is in meq $\mathrm{g}^{-1}$.

2.5.5. Thermogravimetric analysis (TGA). The thermal stability of the SPEEK/PVA composite membranes containing GO was characterized by thermogravimetric analysis (MettlerToledo TGA/SDTA 851). The samples (5-10 mg) were weighed in zirconia crucibles and were heated under a nitrogen atmosphere at a heating rate of $5{ }^{\circ} \mathrm{C} \min ^{-1}$ from an ambient temperature to $750{ }^{\circ} \mathrm{C}$.

2.5.6. Mechanical properties. The mechanical properties of the SPEEK/PVA composite membranes were measured by using a DEBEN microtest tensile module instrument equipped with a 150-N load cell. To avoid the heterogeneity of the sample, five rectangular specimens, $7 \mathrm{~mm} \times 20 \mathrm{~mm}$, were cut from each membrane considering the electrospinning orientation of the fiber mats. The samples were clamped on the tensile module with a separation of $10 \mathrm{~mm}$, and the speed rate was fixed at 0.4 $\mathrm{mm} \min ^{-1}$. The Young's modulus, the maximum tensile strength, the maximum strain and the tenacity were obtained from the tensile stress versus strain plots.

2.5.7. Electrochemical impedance spectroscopy (EIS). The proton conductivity of the membranes in the transversal direction were measured in the temperature range of between 30 and $130{ }^{\circ} \mathrm{C}$ via impedance spectroscopy in the frequency 
interval of $10^{-1}<f<10^{7} \mathrm{~Hz}$, applying a $0.1 \mathrm{~V}$ signal amplitude. A Novocontrol broadband dielectric spectrometer (Hundsangen, Germany) integrated with an SR 830 lock-in amplifier with an alpha dielectric interface was used. The membranes were previously immersed in DI water, and the thickness was measured afterward by using a micrometer, taking the average of 10 measurements at different parts of the surface. Then, the membranes were placed between two gold electrodes in a liquid parallel plate cell coupled to the spectrometer, and DI water was incorporated to ensure a fully hydrated state of the samples below $100{ }^{\circ} \mathrm{C}$ and in equilibrium with its vapor above $100{ }^{\circ} \mathrm{C}$. The temperature was controlled with a nitrogen jet (QUATRO from Novocontrol) with a temperature error of ${ }^{\circ} 0.1 \mathrm{~K}$ during every sweep in frequency.

\section{Results and discussion}

\subsection{Membrane preparation and morphology}

SPEEK/PVA@GO and electrospun SPEEK/PVA@GO-NF were prepared as shown in Fig. 1. The electrospinning process is simple and controllable, and it allows for the large-scale production of the cost-effective nanofiber-reinforced SPEEK/ PVA-based membranes. On the one hand, SPEEK/PVA@GO composite membranes were prepared by embedding a GO layer of $5-7 \mu \mathrm{m}$ in a $\mathrm{SPEEK}_{70}-\mathrm{PVA}_{30}$ polymer solution and subsequently dried at $80{ }^{\circ} \mathrm{C}$ (Fig. 1A). On the other hand, composite materials containing SPEEK/PVB nanofiber mats were also prepared (Fig. 1B), as the incorporation of nanofiber mats into the SPEEK/PVA matrix has been probed to improve mechanical stability and proton conductivity. ${ }^{48,49}$ For the preparation of the SPEEK/PVA@GO-NF composite membrane, SPEEK $_{70}-\mathrm{PVB}_{30}$ nanofibers were initially prepared using the electrospinning method, ${ }^{50}$ controlling different nanofiber mat thicknesses (from 10 to $50 \mu \mathrm{m}$ ) by varying the electrospinning time. Next, the nanofiber mats were sandwiched into two GO layers $(5-7 \mu \mathrm{m})$. Finally, these mats were embedded in a SPEEK ${ }_{70}-\mathrm{PVA}_{30}$ polymer solution and dried at $80{ }^{\circ} \mathrm{C}$.

The images of SPEEK/PVA composite membranes containing GO layers (SPEEK/PVA@GO) reveal relatively uniform and smooth cross-section features (Fig. 2A and ESI Fig. S1†). The SEM images of the composite membranes show some wrinkles at high magnification, consistent with the typical GO nanosheet morphology. ${ }^{51}$ The morphology of composite membranes containing electrospun SPEEK/PVA@GO-NF in Fig. 2B shows that the SPEEK/PVB nanofibers formed a three-dimensional multilayered fibrous network. The thickness of this nanofiber network can be controlled by the variation of the
(A)

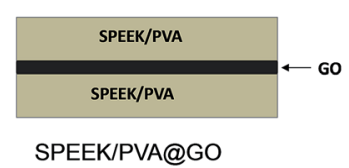

(B)

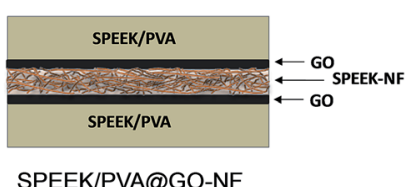

Fig. 1 Schematic representation of SPEEK/PVA composite membranes. electrospinning time. From the micrographs (B and C), it is possible to observe that the nanofiber layer is properly embedded into the SPEEK/PVA polymer matrix (ESI Fig. S2 $\dagger$ ). SEM micrographs also show that a homogeneous morphology for the SPEEK-PVB nanofiber mats was obtained without defects during the electrospinning process (Fig. 2D and E, and ESI Fig. S3†).

\subsection{Physicochemical properties}

The main goal of SPEEK-based proton exchange membranes is the ability to transport or conduct protons $\left(\mathrm{H}^{+}\right)$by using the acidic sulfonic groups $\left(-\mathrm{SO}_{3} \mathrm{H}\right)$ present in the polymer structure, and through the water molecules retained in the network. Table 1 summarizes the total thickness, water uptake, swelling ratio and IEC for the SPEEK/PVA@GO and SPEEK/PVA@GO-NF membranes. The water uptake, swelling ratio and IEC values for a pure SPEEK/PVA membrane are also shown for the sake of comparison. As mentioned above, the water molecules are involved in the conductivity process, and consequently, water uptake is one of the most important properties of sulfonic acidbased polymer membranes in their applicability as fuel cell electrolytes, reflecting the hydrophilicity and free volume property of the membranes. ${ }^{52}$ The water uptake and swelling ratio of membranes were determined via the measurement of the change in the mass and size before and after hydration $(24 \mathrm{~h}$ in DI water), and the obtained values of all of the membranes are shown in Table 1.

Composite membrane SPEEK/PVA@GO showed a higher water uptake value than that of neat SPEEK/PVA. It was also observed that nanocomposite membranes absorb more water compared with SPEEK control membranes, similarly to other SPEEK nanocomposite membranes. ${ }^{53}$ For composite membranes with SPEEK/PVB nanofibers, both the water uptake and swelling degree increased as a function of the nanofiber thickness. As shown in Table 1, the water uptake for SPEEK/ PVA@GO-NF membranes increased from 34 to $47 \%$ when increasing the nanofiber thickness from 10 to $50 \mu \mathrm{m}$. This may be associated with the increasing amount of SPEEK when the thickness of the nanofiber increases, which can favor the hydration process.

The IEC, which is also related to the proton conductivity, indicates the density of exchangeable $\mathrm{H}^{+}$functional groups contained in the polymeric membrane. ${ }^{54}$ The IEC values of prepared membranes are also shown in Table 1. The SPEEK/ PVA matrix displays an IEC of $1.93 \mathrm{mmol} \mathrm{g}^{-1}$. By comparison, the incorporation of GO resulted in a decrease of the IEC value of the SPEEK/PVA@GO membrane, which was $1.74 \mathrm{mmol} \mathrm{g}^{-1}$, as the $\mathrm{GO}$ reduced the $-\mathrm{SO}_{3} \mathrm{H}$ concentration in the composite membrane. ${ }^{55}$ A similar situation was observed for the SPEEK/ PVA@GO-NF systems, where increasing the thickness of this nanofiber network from 10 to $50 \mu \mathrm{m}$ leads to an increase from 1.65 to $1.87 \mathrm{mmol} \mathrm{g}^{-1}$.

Composite membrane SPEEK/PVA@GO showed higher water uptake than that of neat SPEEK/PVA. It was also observed that all of the nanocomposite membranes can absorb more water than the SPEEK/PVA membrane can as observed in 

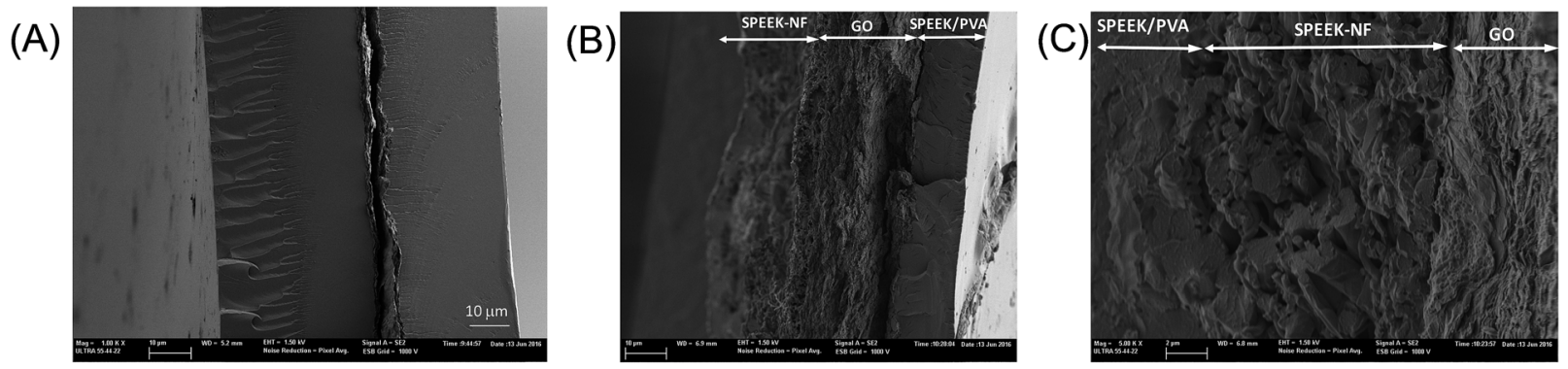

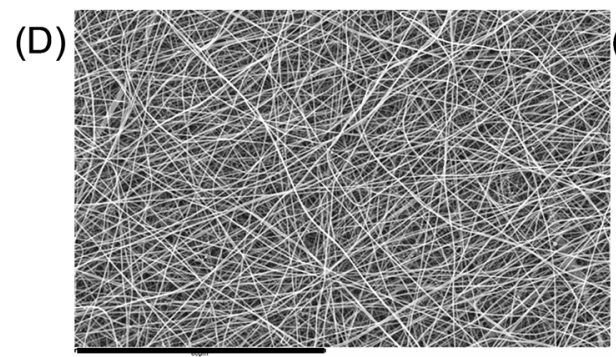

$60 \mu \mathrm{m}$

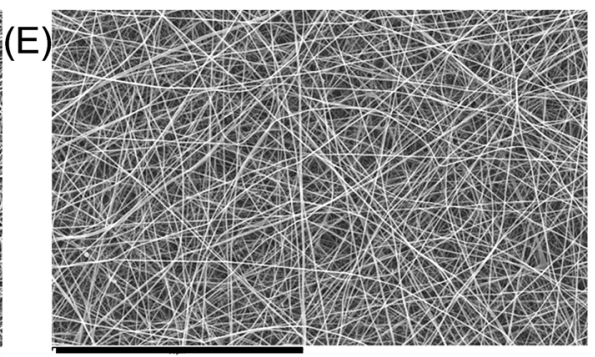

$80 \mu \mathrm{m}$

Fig. 2 SEM images of (A) SPEEK/PVA@GO, (B and C) SPEEK/PVA@GO-NF and (D and E) electrospun fiber mat prepared with 20 wt\% SPEEK $70^{-}$ $\mathrm{PVB}_{30}$ in DMAc for the sample with $12 \mathrm{~h}$ of electrospinning time.

other SPEEK nanocomposite membranes. ${ }^{56}$ For composite membranes with SPEEK/PVB nanofibers, both the water uptake and swelling degree increased as a function of the nanofiber thickness. As shown in Table 1, the water uptake for SPEEK/ PVA@GO-NF membranes increased from 34 to $47 \%$ when increasing the thickness of this nanofiber network from 10 to 50 $\mu \mathrm{m}$. Finally, the degree of sulfonation increased for the SPEEK/ PVA@GO-NF membranes as a function of the nanofiber thickness, from 55 to $64 \%$ as the thickness of this nanofiber network from 10 to $50 \mu \mathrm{m}$.

\subsection{Fourier transform infrared spectra}

Infrared spectroscopy is a highly useful characterization technique in material science. Fig. 3 shows the FT-IR spectra of SPEEK/PVA and SPEEK/PVA@GO-NF membranes over the range of $3750-400 \mathrm{~cm}^{-1}$. For the SPEEK/PVA membrane (Fig. 3a), a broad peak of around $3450 \mathrm{~cm}^{-1}$ due to the presence of $-\mathrm{OH}$ (from $-\mathrm{SO}_{3} \mathrm{H}$ ), and bands at $1286 \mathrm{~cm}^{-1}$ and $1083 \mathrm{~cm}^{-1}$, which are associated with asymmetrical and symmetrical stretching vibrations of the $\mathrm{O}=\mathrm{S}=\mathrm{O}$ group, were observed. After the incorporation of the GO layer, the presence of GO in the membranes was confirmed via the presence of peaks at 3500$3000 \mathrm{~cm}^{-1}$ (O-H stretching), $1590 \mathrm{~cm}^{-1}$ (-COO- stretching) and $1158 \mathrm{~cm}^{-1}$ (C-OH stretching).

All of the SPEEK-based membranes showed characteristic bands assigned to the asymmetric and symmetric stretching vibration of the characteristic bands for $\mathrm{O}=\mathrm{S}=\mathrm{O}$ in the sulfonic acid group. It is worth mentioning that the corresponding bands are slightly shifted to lower wavenumbers, indicating the formation of hydrogen bonds between the sulfonated acid groups from the SPEEK matrix and the polar groups (-OH and $-\mathrm{COOH}$ ) present in the GO layer. ${ }^{57}$ These hydrogen bond interactions may improve the composite membranes' mechanical and thermal stability.

\subsection{Thermal analysis and mechanical properties}

Stable polymer electrolyte membranes that exhibit fast proton transport at high temperatures are required for their application as PEMFCs. The thermal properties of SPEEK-based membranes with GO were studied with TGA (Fig. 4). The

Table 1 Membrane thickness, water uptake (at $25^{\circ} \mathrm{C}$ ), swelling degree, IEC and degree of sulfonation (DS) for SPEEK/PVA@GO and SPEEK/ PVA@GO-NF membranes containing nanofibers with different thicknesses (10, 20, 30 and $50 \mu \mathrm{m})$

\begin{tabular}{lllrl}
\hline Sample & Thickness $(\mu \mathrm{m})$ & Water uptake $(\%)$ & Swelling degree $(\%)$ & IEC $\left(\mathrm{mmol} \mathrm{g}^{-1}\right)$ \\
\hline SPEEK/PVA & $170 \pm 8$ & $28 \pm 3$ & $18 \pm 1$ & $1.93 \pm 0.05$ \\
SPEEK/PVA@GO & $190 \pm 7$ & $37 \pm 2$ & $23 \pm 1$ & $66 \pm 1$ \\
SPEEK/PVA@GO-NF-10 & $210 \pm 11$ & $34 \pm 2$ & $22 \pm 1$ & $58 \pm 1$ \\
SPEEK/PVA@GO-NF-20 & $200 \pm 9$ & $37 \pm 3$ & $28 \pm 2$ & $1.65 \pm 0.03$ \\
SPEEK/PVA@GO-NF-30 & $220 \pm 10$ & $42 \pm 2$ & $26 \pm 1$ & $1.74 \pm 0.02$ \\
SPEEK/PVA@GO-NF-50 & $187 \pm 7$ & $47 \pm 3$ & $25 \pm 2$ & $55 \pm 1$ \\
\end{tabular}




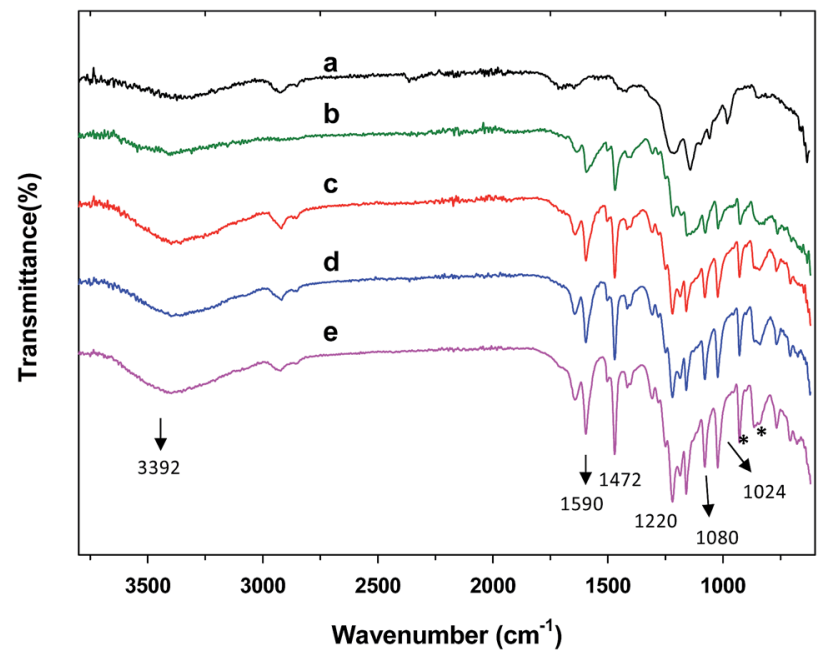

Fig. 3 FT-IR spectra of (a) SPEEK/PVA@GO and SPEEK/PVA@GO-NF with different nanofiber thicknesses ((b) 10, (c) 20, (d) 30 and (e) 50 $\mu \mathrm{m})$.

SPEEK/PVA thermogram shows the three main stages of thermal degradation that these polymer-based membranes undergo. The first stage corresponds to the thermal dissolution at the temperature range from 100 to $200{ }^{\circ} \mathrm{C}$, where all of the water and solvent evaporate. The next stage corresponds to thermal desulfonation at $220-350{ }^{\circ} \mathrm{C}$ (ref. 58) with a weight loss of $16 \%$. Finally, SPEEK/PVA shows one decomposition stage above $450{ }^{\circ} \mathrm{C}$ with $55 \%$ residue, which is attributed to polymer backbone degradation. GO presents a rich variety of functional groups containing oxygen, such as epoxy, hydroxyl, carbonyl and carboxylic acid groups, which can be decomposed via heat treatment, where large changes in weight due to the decomposition of oxygen functional groups were measured from 150 to $300{ }^{\circ} \mathrm{C}$.

With the incorporation of the GO layer into the SPEEK/PVA membrane (SPEEK/PVA@GO) and SPEEK nanofibers (SPEEK/ PVA@GO-NF-30), the second decomposition temperature stage

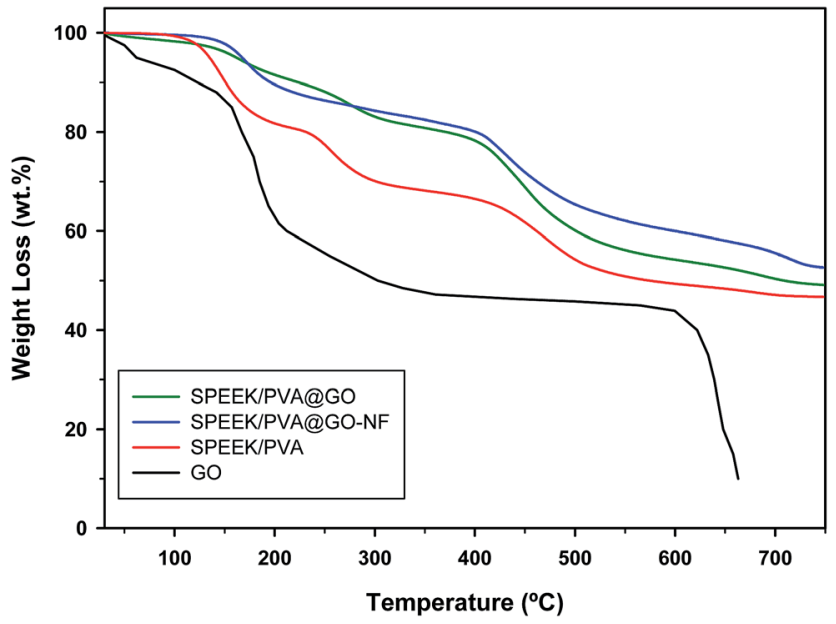

Fig. 4 TGA curves of composite membranes under a $\mathrm{N}_{2}$ atmosphere. of around $220-350{ }^{\circ} \mathrm{C}$ showed weight loss of 12 and $5 \%$, respectively, indicating an improvement of the thermal stability, particularly for the SPEEK/PVA@GO-NF membrane. The result suggests that the presence of GO and nanofibers delays the decomposition of the SPEEK/PVA membrane. It is worth mentioning that composite membranes show higher degradation temperatures than the pure SPEEK/PVA membrane does at the first weight-loss stage, showing an increase in thermal stability. It has been reported that the free radicals can be generated during thermal decomposition and that the GO can capture them, ${ }^{59}$ thus improving the thermal stability of the membrane. The aforementioned results indicate that the interaction between sulfonic acid groups and GO (as shown in the FT-IR spectra) causes an increase in the SPEEK-based membrane's thermal stability. ${ }^{60}$

The mechanical behavior of the membranes was studied by using a DEBEN microtest tensile module instrument. After obtaining the tensile stress versus strain curves (Fig. 5), mechanical parameters, such as Young's modulus, the maximum tensile strength, the maximum strain and the toughness, were obtained (see ESI, Table. S1 $\dagger$ ). These studies were performed with the purpose of evaluating the mechanical behavior and comparing the effect of the incorporation of the GO layer into composite membranes. In the case of the SPEEK/ PVA@GO membrane, an engineering tensile strength at break of 68.9 MPa and a few-percent elongation at break was measured. The incorporation of the nanofiber layer (SPEEK/ PVA@GO-NF) promotes an increase in strength and stiffness, especially for membranes with higher thickness, compared with pure SPEEK-PVA membranes. However, as TGA studies showed, membranes containing SPEEK/PVB nanofibers reveal better stability at high temperatures than SPEEK/PVA@GO membranes do. In this regard, SPEEK/PVA@GO-NF membranes revealed lower engineering tensile strengths at break, which was found to be dependent on the SPEEK/PVB nanofiber thickness (Fig. 5). In addition, Young's modulus increased from 1.4 GPa to 2.1 GPa when increasing the nanofiber thickness from 10 to $50 \mu \mathrm{m}$ respectively. The same trend

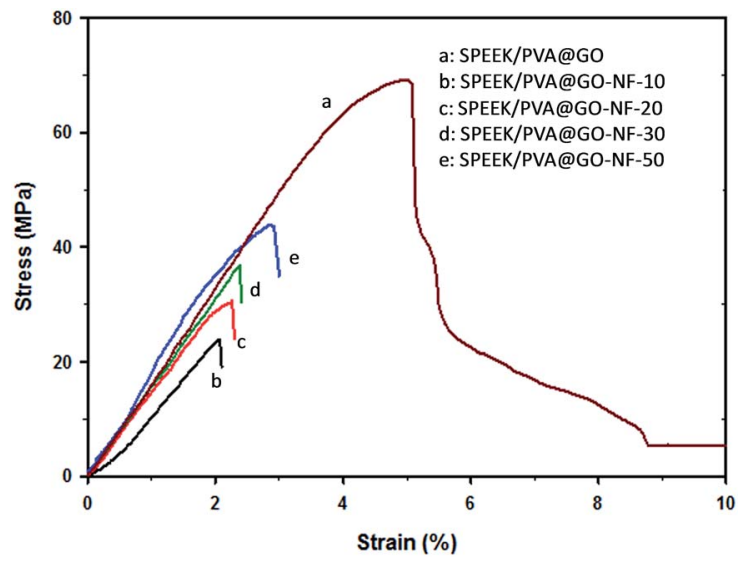

Fig. 5 Tensile stress vs. strain curves obtained from tensile microtests for SPEEK/PVA@GO membrane and SPEEK/PVA-GO-SPEEK-NF membranes with different SPEEK/PVA nanofiber thicknesses (10, 20, 30 and $50 \mu \mathrm{m})$. 
was observed for the maximum tensile strength, whose value increased from 23.8 to $43.5 \mathrm{MPa}$ respectively for the same thickness increment. These values suggest that the incorporation of the SPEEK/PVB nanofiber layer promotes an increase in strength, compared with the SPEEK-PVA pure membrane, which breaks abruptly. These results are in agreement with previous studies regarding the nanofiber mats of SPEEK/PVB composite membranes. As a result of the mechanical tests, all composite membranes prepared are mechanically stable and suitable candidates in PEMFC applications.

\subsection{Electrochemical impedance spectroscopy (EIS)}

Electrochemical impedance spectroscopy (EIS) is an experimental method for characterizing electrochemical systems, involving measuring the impedance of the electrochemical system over a range of frequencies, and therefore, the frequency response of the system can be determined. ${ }^{\mathbf{6 1}}$ Although EIS is considered an indirect methodology, it is commonly used to determine the ion conductivity in polyelectrolyte membranes. EIS is an indirect method because it requires the selection of criteria to obtain the true value of the DC conductivity. In this regard, from the dielectric measurements taken with the Novontrol equipment (from 0.1 to $10 \mathrm{MHz}$ ), the DC conductivity, $\sigma_{\mathrm{dc}}$, can be obtained by using three methodologies: (1) from the relationship between the complex dielectric permittivity and the complex conductivity, (2) from the Bode diagram and (3) from the Nyquist plot. After determining $\sigma_{\mathrm{dc}}$ via the three methodologies described above, the average values are reported in Table 2 .

Table 2 Values of the diffusion coefficient, activation energy and conductivity obtained via $\varepsilon^{\prime \prime}$ vs. frequency Bode and Nyquist diagrams and plots for SPEEK/PVA@GO and SPEEK/PVA@GO-NF membranes

\begin{tabular}{llc}
\hline Sample & $T\left({ }^{\circ} \mathrm{C}\right)$ & $\sigma_{\mathrm{dc}} \times 10^{-3}\left(\mathrm{~S} \mathrm{~cm}^{-1}\right)$ \\
\hline SPEEK/PVA@GO & 30 & $1.10 \pm 0.02$ \\
& 50 & $2.7 \pm 0.1$ \\
& 70 & $3.60 \pm 0.2$ \\
& 90 & $6.0 \pm 0.4$ \\
SPEEK/PVA@GO-NF-10 & 110 & $7.6 \pm 0.4$ \\
& 130 & $8.3 \pm 0.6$ \\
& 30 & $0.02 \pm 0.07$ \\
& 50 & $0.03 \pm 0.10$ \\
SPEEK/PVA@GO-NF-30 & 70 & $0.05 \pm 0.05$ \\
& 90 & $0.07 \pm 0.12$ \\
& 110 & $0.09 \pm 0.13$ \\
& 130 & $0.12 \pm 0.02$ \\
& 30 & $0.5 \pm 0.1$ \\
& 50 & $0.9 \pm 0.1$ \\
SPEEK/PVA@GO-NF-50 & 70 & $1.4 \pm 01$ \\
& 90 & $1.8 \pm 0.2$ \\
& 110 & $2.0 \pm 0.1$ \\
& 130 & $2.2 \pm 0.1$ \\
& 30 & $0.9 \pm 0.1$ \\
& 50 & $1.6 \pm 0.1$ \\
& 70 & $2.5 \pm 0.2$ \\
& 90 & $3.8 \pm 0.2$ \\
& 110 & $4.9 \pm 0.2$ \\
& 130 & $5.3 \pm 0.2$
\end{tabular}

Initially, the DC conductivity $\left(\sigma_{\mathrm{dc}}\right)$ was calculated from the relationship between the complex dielectric permittivity and the complex conductivity, which is given by eqn (5):

$$
\sigma^{*}(\omega, T)=\mathrm{j} \varepsilon_{0} \omega \varepsilon^{*}(\omega, T)
$$

This equation can also be expressed in terms of the real and imaginary part, taking into account the dielectric permittivity $\varepsilon^{*}(\omega)=\varepsilon^{\prime}(\omega)-\mathrm{j} \varepsilon^{\prime \prime}(\omega)$, as follows in eqn (6) and (7):

$$
\begin{aligned}
\sigma^{\prime} & =\varepsilon_{0} \omega \varepsilon^{\prime \prime} \\
\sigma^{\prime \prime} & =\varepsilon_{0} \omega \varepsilon^{\prime}
\end{aligned}
$$

where $\varepsilon_{0}$ represents the vacuum permittivity and $\omega$ the angular frequency of the applied electric field $(\omega=2 \pi f)$. The real part of conductivity, $\sigma^{\prime}$, is characterized in the high-frequency range by a plateau that represents the sample's DC conductivity $\left(\sigma_{\mathrm{dc}}\right)$.

Nevertheless, the determination of conductivity from the imaginary part of the complex dielectric permittivity, where the slope of $\log \varepsilon^{\prime \prime}$ versus $\log \omega$ is equal to -1 , allowed us to obtain a solid estimation of the DC conductivity when the MaxwellWagner-Sillar (MWS) effects due to the bulk conductivity dominate as for a pure ohmic conduction. ${ }^{62-65}$ Notice that the intercept of this straight line at $\log \omega=0$ allowed for determining the value of DC conductivity $\left(\sigma_{\mathrm{dc}}\right)$, as for the "idealized" case of a compound with purely ohmic conductivity, the imaginary part of the complex permittivity is provided by $\varepsilon^{\prime \prime}=\sigma_{\delta \chi} /$ $\left(\varepsilon_{0} \omega\right)$. This can be seen by the fact that the plot of the double logarithm plot of the dielectric loss versus frequency exhibits a slope of -1 (ESI, Fig. S9-S10 ${ }^{\dagger}$ ). As a representative example, Fig. 6 shows the double logarithmic plot of the imaginary permittivity $\varepsilon^{\prime \prime}$ versus the frequency for the SPEEK/PVA@GO membrane at all temperatures under study $\left(30-130{ }^{\circ} \mathrm{C}\right)$. As shown, the behavior of the SPEEK/PVA@GO membrane is linear in the region of high frequency. The slope of the straight line is practically -1 for all of the temperatures studied (values from

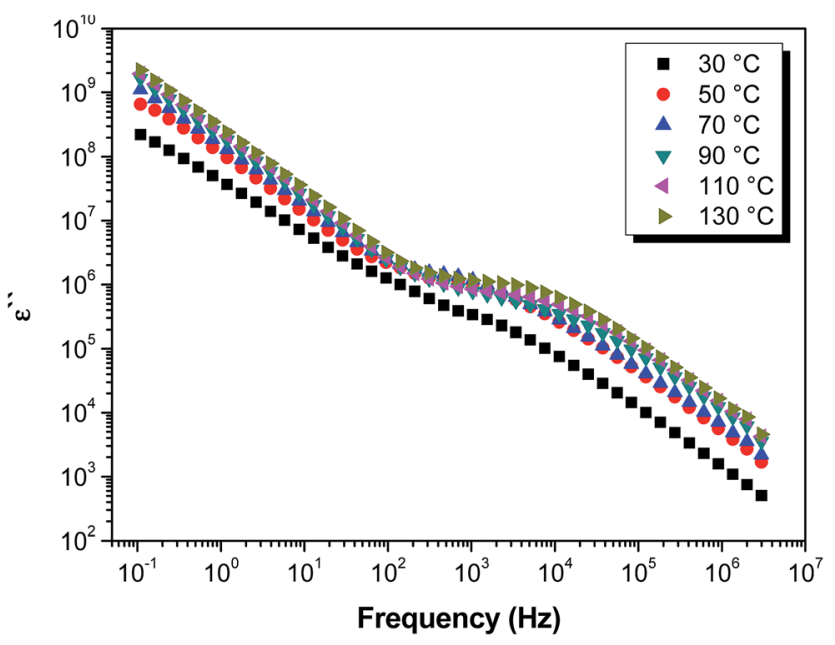

Fig. 6 Double logarithmic plot of the imaginary permittivity $\varepsilon^{\prime \prime}$ versus the frequency for the SPEEK/PVACGO membrane in the temperature range between 30 and $130{ }^{\circ} \mathrm{C}$. 
-0.97 to -1 , with a correlation coefficient of 0.999$)$. From the double logarithm plots of the imaginary permittivity $\varepsilon^{\prime \prime}$ versus frequency, $\sigma_{\mathrm{dc}}$ can be obtained from the intercept at frequency $f=1 \mathrm{~Hz}$ (when the $\log f=0$ ). Following this procedure, the conductivities $\left(\sigma_{\mathrm{dc}}\right)$ of the composite membranes and 30 to $130{ }^{\circ} \mathrm{C}$ were obtained.

Fig. 6 also shows that in the region of mid-frequency, the behavior of $\varepsilon^{\prime \prime}$ passes through a maximum or a saddle point, then continues increasing with decreasing frequency. This shoulder of the complex permittivity $\left(\varepsilon^{\prime \prime}\right)$ shows a Debye-like shape, due to the electrode polarization (EP) effect, characterized by relaxation time $\tau_{\mathrm{EP}}$ that depends on the temperatures, sample widths and chemical structures of materials and their properties. The maximum in $\varepsilon^{\prime \prime}$ represents the full development of the electrode polarization. ${ }^{\mathbf{6 6 , 6 7}}$ For the other samples described in the study, a similar behavior was observed (ESI Fig. S9-S10†). From these figures, we observe the peak or shoulder shift to low frequencies as the temperature increases. However, when the temperature is higher than $100{ }^{\circ} \mathrm{C}$, this behavior changes, and the shoulder shift to high frequencies may be related to the samples' dryness.

At low frequencies, the dependence is, again, linear, but with a slope lower than unity, which is an indication of dependence similar to what happens in the high-frequency region following eqn (8):

$$
\varepsilon^{\prime \prime}=\frac{\sigma^{\prime}}{\varepsilon_{0} \omega^{n}}
$$

where $n$ takes values between 0.5 and 0.7 but with conductivity $\sigma^{\prime}$ associated with other types of ions, such as impurities that diffuse more slowly because the EP has almost completely built up. ${ }^{68}$

As mentioned above, another commonly used methodology for determining the DC conductivity is from the Bode diagram. ${ }^{69}$ As shown in Fig. 7 for all samples, the real part of the conductivity, $\sigma^{\prime}$, and the phase angle $(\phi)$ are represented in function of the frequency for all temperatures studied. A closer inspection of these plots shows that the values of the real part of the conductivity reach a plateau when the phase angle tends to be a value of zero. In our samples, we can observe a plateau, situated in the region of high frequencies (when samples are in wet conditions) and at low frequencies when the samples are measured in dry conditions. Both plateaus are associated with the ionic conductivity in the bulk of the samples, $\sigma_{\mathrm{dc}}$, reflecting long-range ionic transport. ${ }^{\mathbf{0}-72}$

The analysis of Bode plots (Fig. 7) yielded information complementing that obtained from imaginary permittivity $\varepsilon^{\prime \prime}$ plots. In Bode plots, the real part of the conductivity $\left(\sigma^{\prime}\right)$ and the phase angle $(\phi)$ are represented as a function of the frequency. Ideally, the proton conductivity of the membrane can be obtained from the value of the conductivity in the region of high frequencies where the phase angle reaches zero. Accordingly, we obtained the proton conductivity from the Bode plots, where the phase angle was close to -15 . A closer inspection of Fig. 7 shows that the values of the real part of the conductivity $\left(\sigma^{\prime}\right)$ reach a plateau in the region of low frequencies (when the phase angle $(\phi)$ tends to be zero) and others in the region of low frequencies. The plateau situated in the region of high frequencies is associated with the protonic conductivity in the bulk SPEEK/PVA pure membrane. The other plateau in the region of low frequencies can be associated with the proton conductivity trough of the SPEEK/PVB nanofibers and also with the electrode polarization via the formation of electrochemical double layers and polymer relaxation. Between the regions of high and low frequency, there is a decrease in the conductivity that can be explained as a Debye relaxation due to the macroscopic polarization of the ionic charges as a consequence of the applied electric field. This relaxation is characterized by a relaxation time that is dependent on the temperature, the chemical structure of the membrane and its thickness. ${ }^{73}$

Although the maximum conductivity for the obtained composite membrane with GO is lower than those reported to commercial Nafion membranes at temperatures below $90{ }^{\circ} \mathrm{C}$, the importance of these SPEEK/PVA@GO composite membranes is that these membranes can operate in a temperature range of 90 to $130{ }^{\circ} \mathrm{C}$, maintaining good proton conductivity and stability without being susceptible to degradation at these temperatures. This advantage makes these novel composite membranes suitable candidates for applications in fuel cells at intermediate temperatures, especially in the range from 100 to $130{ }^{\circ} \mathrm{C}$.

Finally, we also looked at the Nyquist diagram ${ }^{74}$ for the same temperatures represented in the Bode diagram of conductivities. In the Nyquist plot, the real $\left(Z^{\prime}\right)$ and imaginary components $\left(Z^{\prime \prime}\right)$ of the complex impedance were plotted for the entire range of frequencies. We can observe for all of the composite membranes and for all temperatures two semicircles intersecting the abscissa axis in the high-frequency region at $Z^{\prime}=R_{0}$ (i.e., the membrane resistance). Semicircle-like waves are observed as a result of polarization processes, the two possible relaxation processes associated with the bulk and nanofiber components, and other phenomena taking place in the system composed of the SPEEK/PVB nanofiber-SPEEK/PVA bulk-electrode interface. The following equation was calculated (9):

$$
\sigma^{\prime}=\frac{L}{R_{\mathrm{o}} \cdot S}
$$

where $L$ is the thickness of the sample, and $S$, the effective area of the sample sandwiched between the two electrodes during measurements, have also been permitted to obtain the conductivity values (ESI Fig. S16-S19†). Table 2 shows the average values of the conductivities obtained for all of the temperatures studied via the aforementioned methods: (1) the double logarithm plot of the dielectric loss versus frequency, (2) Bode diagram and (3) Nyquist plot are given.

Finally, we investigated the relationship between proton conductivity and temperature. For this purpose, we measured the conductivity in the range of $30-130{ }^{\circ} \mathrm{C}$. We found that the proton conductivity of SPEEK/PVA@GO membranes increased with temperature, as the mobility of conducting species increases with higher temperatures. In this particular study, the proton conductivity increased from $1 \times 10^{-3} \mathrm{~S} \mathrm{~cm}^{-1}$ at $30^{\circ} \mathrm{C}$ to $8.3 \times 10^{-3} \mathrm{~S} \mathrm{~cm}^{-1}$ at $130{ }^{\circ} \mathrm{C}$. These values are higher than the values observed for composite SPEEK/PVA@GO-NF membranes 

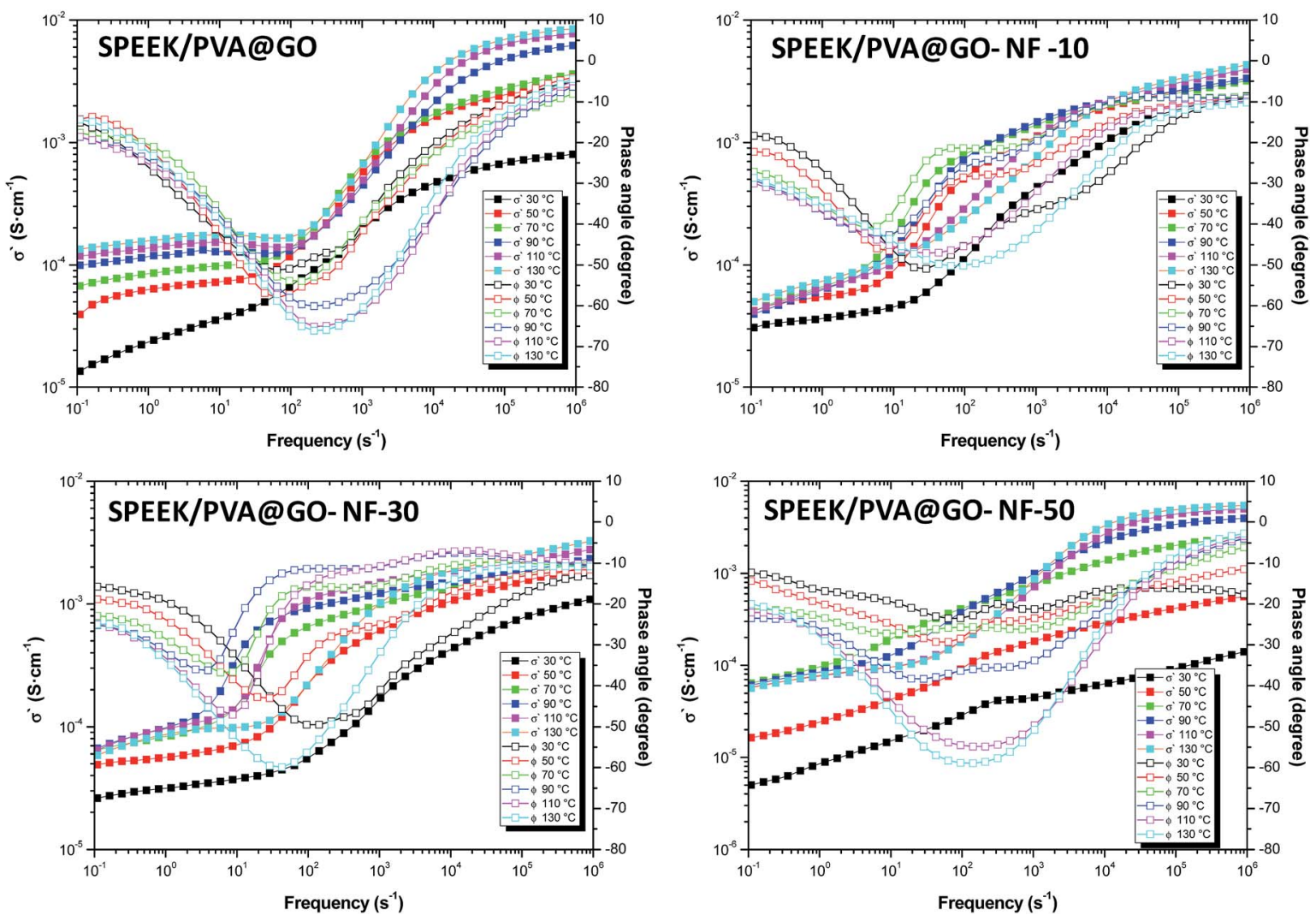

Fig. 7 Bode diagram for the SPEEK/PVA@GO and SPEEK/PVA@GO-NF composite membranes at several temperatures: 30, 50, 70, 90, 110 and $130^{\circ} \mathrm{C}$.

containing SPEEK/PVA nanofibers. For the latter, a conductivity comparison between the SPEEK/PVA@GO-NF membranes with different nanofiber thickness allowed us to conclude that conductivity increased with nanofiber thickness at all temperatures under study. This behavior was associated with the contribution of the nanofibers to the conductivity of the composite membrane. Although the proton conductivity of SPEEK/PVA@GO-NF membranes is low compared with commercial membranes based on Nafion or in the range of SPEEK-PVA pure membranes, the conductivity for Nafion drops significantly at $80{ }^{\circ} \mathrm{C}$. On the contrary, the conductivity of SPEEK/PVA@GO-NF membranes can operate at temperatures of more than $100{ }^{\circ} \mathrm{C}$. These results show that the incorporation of GO clearly offers substantial PEMFC and DMFC performance improvements at elevated temperatures.

As shown in Fig. 8, the relationship between proton conductivity and temperature follows a Vogel-Fulcher-Tammann (VFT) behavior according to eqn (10):

$$
\ln \sigma^{\prime}=\ln \sigma_{\infty}-\frac{B}{T-T_{0}}
$$

where $\sigma_{\infty}$ is a pre-factor related to the conducting limit at higher temperatures, $B$ is a fitting parameter related to the curvature of the plot, which can be described as the activation energy of the process, and $T_{0}$ is the Vogel temperature, considered the temperature where the relaxation time would diverge.
Table 3 shows the corresponding VFT parameters, $\sigma_{\infty}, B$ and $T_{0}$, for the conductivity data of the composite membranes for the entire range of temperatures. The calculated activation energy are also shown, and the SPEEK/PVA@GO membrane displays an activation energy of $1.4 \mathrm{~kJ} \mathrm{~mol}^{-1}$, which was found to be one order of magnitude lower than that obtained for pure SPEEK/PVA, whose value is $17.3 \mathrm{~kJ} \mathrm{~mol}{ }^{-1}$. This significant

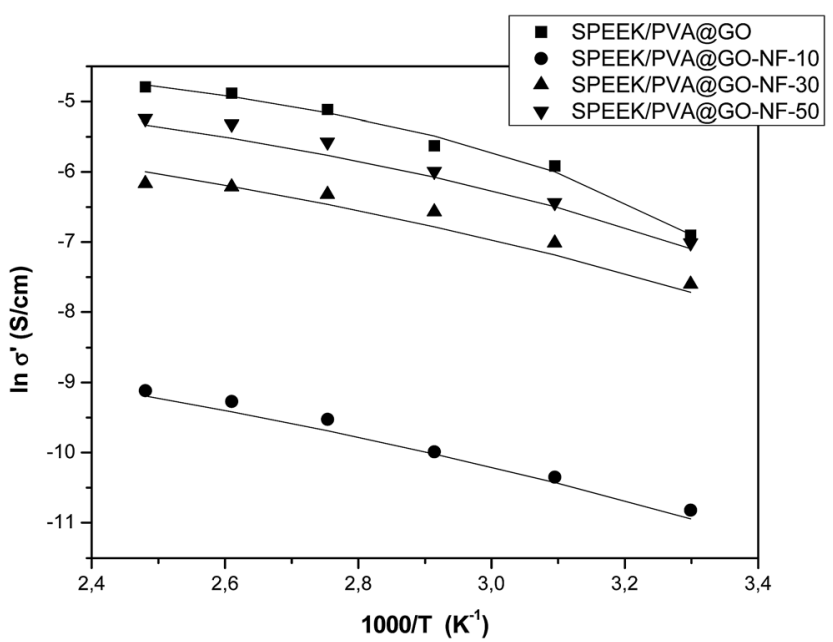

Fig. 8 Arrhenius plot for the SPEEK/PVA composite membranes containing GO. 
Table 3 Vogel-Fulcher-Tammann (VFT) fitting parameters obtained from the membranes under study. The values of $\chi^{2}$ parameters represent the sum of the square deviations between the experimental data and theoretical values determined using eqn (10)

\begin{tabular}{|c|c|c|c|c|c|}
\hline Sample & $\ln \sigma_{\infty}\left(\mathrm{S} \mathrm{cm}^{-1}\right)$ & $B(\mathrm{~K})$ & $T_{0}(\mathrm{~K})$ & $\chi^{2}$ & $E_{\text {act }}\left(\mathrm{kJ} \mathrm{mol}^{-1}\right)$ \\
\hline SPEEK/PVA@GO & 0.026 & 171 & 250 & 0.03 & $1.4 \pm 0.1$ \\
\hline SPEEK/PVA@GO-NF-10 & 0.0013 & 629 & 158 & 0.1 & $5.2 \pm 0.1$ \\
\hline SPEEK/PVA@GO-NF-50 & 0.025 & 325 & 208 & 0.1 & $2.7 \pm 0.1$ \\
\hline
\end{tabular}

reduction in the activation energy indicates that the influence of temperature on the conductivity decreased when the GO layer was inserted into SPEEK/PVA membranes. In the case of SPEEK/ PVA@GO-NF membrane, the activation energy decreased as a function of the thickness of the nanofiber network. In this regard, the activation energy varied from 5.2 to $2.7 \mathrm{~kJ} \mathrm{~mol}^{-1}$ when increasing the nanofiber thickness from 10 to $50 \mu \mathrm{m}$ respectively. This effect suggests that the nanofiber layer favors the proton transport, and therefore, conductivity occurs more easily through the nanofiber network rather than in the SPEEK/ PVA phase.

\section{Conclusions}

In summary, we prepared a membrane consisting of a sandwich of a GO layer inside two SPEEK/PVA layers (SPEEK/PVA@GO) and a sandwich of a SPEEK/PVA nanofiber layer (SPEEK/ PVA@GO-NF) containing nanofiber layers with 10-50 mm thickness inside two GO layers, which was sandwiched inside two SPEEK/PVA layers. The structures of the different SPEEK/ PVA composite membranes were investigated with SEM, FT-IR and TGA. Impedance spectroscopy studies allowed us to obtain the proton conductivity, and the results showed the importance of the nanofiber layer in gaining adequate chemical, thermal and mechanical stabilities. The highest proton conductivity was found for the SPEEK/PVA@GO membrane, 8.3 $\mathrm{mS} \mathrm{cm}{ }^{-1}$ at $130{ }^{\circ} \mathrm{C}$. These results show that the incorporation of GO clearly offers substantial PEMFC performance improvements at elevated temperatures. Further investigations to optimize the performance of these composite membranes are in progress.

\section{Conflicts of interest}

There are no conflicts to declare.

\section{Acknowledgements}

We gratefully acknowledge Ministerio de Economía y Competitividad (MINECO), Spain for financial support via the ENE/ 2015-69203-R project.

\section{Notes and references}

1 S. Hammes-Schiffer and A. V. Soudackov, J. Phys. Chem. B, 2008, 112, 14108-14123.

2 B. C. H. Steele and A. Heinzel, Nature, 2001, 414, 345-352.
3 H. W. Zhang and P. K. Shen, Chem. Rev., 2012, 112, 27802832.

4 S. Zhong, X. Cui, H. Cai, T. Fu, C. Zhao and H. Na, J. Power Sources, 2007, 164, 65-72.

5 S. J. Peighambardoust, S. Rowshanzamira and M. Amjadi, Int. J. Hydrogen Energy, 2010, 35, 9349-9384.

6 A. Kraytsberg and Y. Ein-Eli, Energy Fuels, 2014, 28, 73037330.

7 B. Schwenzer, J. L. Zhang, S. Kim, L. Y. Li, J. Liu and Z. G. Yang, ChemSusChem, 2011, 4, 1388-1406.

8 K. A. Mauritz and R. B. Moore, Chem. Rev., 2004, 104, 45354586.

9 B. Jiang, L. Wu, L. Yu, X. Qiu and J. Xi, J. Membr. Sci., 2016, 510, 18-26.

10 T. Kim, Y.-W. Choi, C.-S. Kim, T.-H. Yanga and M.-N. Kim, J. Mater. Chem., 2011, 21, 7612-7621.

11 K. Matsumoto, T. Higashihara and M. Ueda, Macromolecules, 2009, 42, 1161-1166.

12 T. Ko, K. Kim, B. K. Jung, S. H. Cha, S. K. Kim and J. C. Lee, Macromolecules, 2015, 48, 1104-1114.

$13 \mathrm{~J}$. Kerres and V. Atanasov, Int. J. Hydrogen Energy, 2015, 40, 14723-14735.

14 S. S. Araya, F. Zhou, V. Liso, S. L. Sahlin, J. R. Vang, S. Thomas, X. Gao, C. Jeppesen and S. K. Kær, Int. J. Hydrogen Energy, 2016, 41, 21310-21344.

15 Y. P. Zhang, M. Z. Yue and Y. Chen, Adv. Mater. Res., 2011, 239-242, 3032-3038.

16 H. R. Allcock and R. M. Wood, J. Polym. Sci., Part B: Polym. Phys., 2006, 44, 2358-2368.

17 Z. Li, W. Dai, L. Yu, J. Xi, X. Qiu and L. Chen, J. Power Sources, 2014, 257, 221-229.

18 X. Li, H. Zhang, Z. Mai, H. Zhang and I. Vankelecom, Energy Environ. Sci., 2011, 4, 1147-1160.

19 M. A. Hickner, H. Ghassemi, Y. S. Kim, B. R. Einsla and J. E. McGrath, Chem. Rev., 2004, 104, 4587-4612.

20 S. D. Mikhailenko, K. Wang, S. Kaliaguine, P. Xing, G. P. Robertson and M. D. Guiver, J. Membr. Sci., 2004, 233, 93-99.

21 V. R. Hande, S. K. Rath, S. Rao and M. Patri, J. Membr. Sci., 2011, 372, 40-48.

22 C. Laberty-Robert, K. Valle, F. Pereira and C. Sanchez, Chem. Soc. Rev., 2011, 40, 961-1005.

23 J. Xi, Z. Li, L. Yu, B. Yin, L. Wang, L. Liu, X. Qiu and L. Chen, J. Power Sources, 2015, 285, 195-204.

24 E. Şengül, H. Erdener, R. G. Akay, H. Yücel, N. Baç and I. Eroğlu, Int. J. Hydrogen Energy, 2009, 34, 46454652 . 
25 N. Wang, S. Peng, H. Wang, Y. Li, S. Q. Liu and Y. Liu, Electrochem. Commun., 2012, 17, 30-33.

$26 \mathrm{X} . \mathrm{Xu}, \mathrm{L} . \mathrm{Li}, \mathrm{H}$. Wang, X. Li and X. Zhuang, $R S C$ Adv., 2015, 5, 4934-4940.

27 T. Yang and C. Liu, Int. J. Hydrogen Energy, 2011, 36, 56665674.

28 J. C. McKeen, Y. S. Yan and M. E. Davis, Chem. Mater., 2008, 20, 5122-5124.

29 Y. Li, G. He, S. Wang, S. Yu, F. Pan, H. Wu and Z. Jiang, J. Mater. Chem. A, 2013, 1, 10058-10077.

30 E. Bakangura, L. Wu, L. Ge, Z. Yang and T. Xu, Prog. Polym. Sci., 2016, 57, 103-152.

31 Z. Chen, B. Holmberg, W. Li, X. Wang, W. Deng, R. Muñoz and Y. Yan, Chem. Mater., 2006, 18, 5669-5675.

32 C. Gong, X. Zheng, H. Liu, G. Wang, F. Cheng, G. Zheng, S. Wen, W. Law, C. P. Tsui and C. Y. Tang, J. Power Sources, 2016, 325, 453-464.

33 J. Wang, H. Bai, H. Zhang, L. Zhao, H. Chen and Y. Li, Electrochim. Acta, 2015, 152, 443-455.

34 V. Ramani, H. R. Kunz and J. M. Fenton, J. Membr. Sci., 2004, 232, 31-44.

35 R. Raccichini, A. Varzi, S. Passerini and B. Scrosati, Nat. Mater., 2014, 14, 271-279.

36 M. R. Karim, K. Hatakeyama, T. Matsui, H. Takehira, T. Taniguchi, M. Koinuma, Y. Matsumoto, T. Akutagawa, T. Nakamura, S. Noro, T. Yamada, H. Kitagawa and S. Hayami, J. Am. Chem. Soc., 2013, 135, 8097-8100.

37 Y. Kim, K. Ketpang, S. Jaritphun, J. Seo Park and S. Shanmugam, J. Mater. Chem. A, 2015, 3, 8148-8155.

38 K. Oh, B. Son, J. Sanetuntikul and S. Shanmugam, J. Membr. Sci., 2017, 541, 386-392.

39 H. Wu, X. Shen, Y. Cao, Z. Li and Z. Jiang, J. Membr. Sci., 2014, 451, 74-84.

40 Y. He, J. Wang, H. Zhang, T. Zhang, B. Zhang, S. Cao and J. Liu, J. Mater. Chem. A, 2014, 2, 9548-9558.

41 L. Cao, Q. Sun, Y. Gao, L. Liu and H. Shi, Electrochim. Acta, 2015, 158, 24-34.

42 M. A. Aziz, K. Oh and S. Shanmugam, Chem. Commun., 2017, 53, 917-920.

43 W. Dai, Y. Shen, Z. Li, L. Yu, J. Xi and X. Qiu, J. Mater. Chem. A, 2014, 2, 12423-12432.

44 D. H. Reneker and A. L. Yarin, Polymer, 2008, 49, 2387-2425. 45 W. S. Hummers and R. E. Offemann, J. Am. Chem. Soc., 1958, 80, 1339.

46 Y. Xu, H. Bai, G. Lu, C. Li and G. Shi, J. Am. Chem. Soc., 2008, 130, 5856-5857.

47 J. L. Reyes-Rodriguez, O. Solorza-Feria, A. García-Bernabé, E. Giménez, O. Sahuquillo and V. Compañ, RSC Adv., 2016, 6, 56986-56999.

48 S. Mollá and V. Compañ, J. Membr. Sci., 2015, 492, 123-136. 49 S. Mollá and V. Compañ, J. Power Sources, 2011, 196, 26992708.
50 S. Mollá and V. Compañ, Int. J. Hydrogen Energy, 2014, 39, 5121-5136.

51 H. Zarrin, D. Higgins, Y. Jun, Z. W. Chenq and M. Flowler, J. Phys. Chem. C, 2011, 115, 20774-20781.

52 D. Marani, A. D'Epifanio, E. Traversa, M. Miyayama and S. Licoccia, Chem. Mater., 2010, 22, 1126-1133.

53 X. Qiu, T. Dong, M. Ueda, X. Zhang and L. Wang, J. Membr. Sci., 2017, 524, 663-672.

54 C. Zhao, H. Lin, K. Shao, X. Li, H. Ni, Z. Wang and H. Na, J. Power Sources, 2006, 162, 1003-1009.

55 L. Zhao, Y. Li, H. Zhang, W. Wu, J. Liu and J. Wang, J. Power Sources, 2016, 286, 445-457.

56 X. Qiu, T. Dong, M. Ueda, X. Zhang and L. Wang, J. Membr. Sci., 2017, 524, 663.

57 R. Kumar, M. Mamlouk and K. Scott, RSC Adv., 2014, 4, 617623.

58 S. M. J. Zaidi, S. D. Mikhailenko, G. P. Robertson, M. D. Guiver and S. Kaliaguine, J. Membr. Sci., 2000, 173, 17-34.

59 G. Gonçalves, P. A. A. P. Marques, A. Barros-Timmons, I. Bdkin, M. K. Singh, N. Emami and J. Gracio, J. Mater. Chem., 2010, 20, 9927-9934.

60 S. Feng, K. Z. Shen, Y. Wang, J. H. Pang and Z. H. Jiang, J. Power Sources, 2013, 224, 42-49.

61 E. P. Randviir and C. E. Banks, Anal. Methods, 2013, 5, 10981115.

62 J. C. Maxwell, A treatise of Electricity \& Magnetism, Dover, NY, 1954.

63 K. W. Wagner, Arch. Elektrotech., 1914, 2, 371-387.

64 K. W. Wagner, Arch. Elektrotech., 1914, 3, 67-106.

65 R. W. Sillars, Proc. Inst. Electr. Eng., 1937, 80, 378-394.

66 Y. W. Che-Nan, F. Fan, J. R. Sangoro, M. B. Berman, S. G. Greenbaum, T. A. Zawodzinski and A. P. Sokolov, Phys. Rev. E: Stat., Nonlinear, Soft Matter Phys., 2013, 87, 042301.

67 T. S. Sorensen, V. Compañ, R. Diaz-Calleja and E. Riande, J. Appl. Phys., 1996, 79, 403-411.

68 A. Munar, A. Andrio, R. Iserte and V. Compañ, J. Non-Cryst. Solids, 2011, 357, 3064-3069.

69 H. W. Bode, Netwok Analysis and Feedback Amplifier Design, Van Nostrand, Princeton, NJ, 1945.

70 T. S. Sorensen and V. Compañ, J. Chem. Soc., Faraday Trans., 1995, 91, 4235-4250.

71 M. Drüschler, B. Hubber and S. Passerini, J. Phys. Chem. C, 2011, 115, 6802-6808.

72 F. Kremer and A. Schoenhals, Broadband Dielectric Spectroscopy, Springer, Berlin, 2003.

73 J. Klein, S. Zhang, S. Dou, B. H. Jones, R. Colby and J. Runt, Chem. Phys., 2006, 124, 144903.

74 H. Nyquist, Phys. Rev., 1928, 32, 110-113. 